\title{
Investigating the Effect of Metal Nanomaterials on the Moisture Sensitivity Process of Asphalt Mixes
}

\author{
Iraj Bargegol ${ }^{1}$, Farhad Sakanlou², Mohsen Sohrabi², Gholam Hossein Hamedi ${ }^{\text {1* }}$ \\ ${ }^{1}$ Department of Civil Engineering, Faculty of Engineering, University of Guilan, P. O. B. 3756, Rasht, Iran \\ ${ }^{2}$ Department of Civil Engineering, Faculty of Engineering, Urmia University, P. O. B. 165, Urmia, Iran \\ * Corresponding author, e-mail: hamedi@guilan.ac.ir
}

Received: 12 March 2018, Accepted: 13 August 2020, Published online: 21 September 2020

\begin{abstract}
One of the most common damages in asphalt mixes is the destructive effect of moisture on the binder cohesion and binder-aggregate adhesion which is called moisture damage. There are various methods to improve adhesion and reduce moisture damage in asphalt mixes. The most common of them is using an appropriate additive for binder modification. Accordingly, the current research was conducted to investigate the effect of two nanomaterials ( $\mathrm{Nano} \mathrm{CuO}$, and $\mathrm{Nano} \mathrm{SnO}_{2}$ ) in 2 different percentages on 2 types of aggregates (granite and limestone) and a type of base binder. In order to investigate the effect of nanomaterials, indirect tensile cyclic loading (the same as resilient modulus test) in dry and wet conditions and surface free energy (SFE) method were used. The moisture sensitivity indicator which shows stripping percentage of aggregate surface in loading cycles using SFE results and indirect tensile cyclic loading, has been considered as the moisture sensitivity indicator in this research. Results of mechanical tests used in this research show that nanomaterials have significantly increased asphalt mixes strength in comparison to control specimens. Results obtained from SFE method show that nanomaterials increase the cohesion free energy; this change causes a reduction in the possibility of failure in binder membrane. Additionally, nanoparticles have increased and reduced basic component and acidic component of SFE, respectively. This leads to improvement of their adhesion with acidic aggregates, which is sensitive to moisture damage.
\end{abstract}

Keywords

moisture damage, nanomaterials, antistripping additive, indirect tensile cyclic loading

\section{Introduction}

Many road administrations have made a lot of attempts in order to reduce pavements repair and maintenance costs. One of the damages causing high costs of asphalt pavements is moisture damage [1]. Moisture damage, by definition, means the loss of strength and durability in asphalt mixes in the presence of water [2]. One of the important factors in asphalt mixtures failure, is the percentage and properties of materials used in asphalt mix [3, 4]. Accordingly, in recent years, attempts have been made to modify the properties of materials used in asphalt mix. One of the most common methods is the use of hydrated lime and/ or liquid antistripping additives of the family of amines or amidoamines. In the current research attempts have been made to investigate the use of metal nanoma-

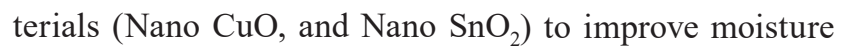
damage of asphalt mixes. The reason of selecting these nanomaterials is due to their alkaline properties which can probably reduce acidic properties of binder and decrease moisture damage of asphalt mixes. Nanotechnology is used in design, construction and operation of practical materials with at least one of the dimensions determined in the nanometer unit [5]. This technology is continuously expanding with the advancement of sciences and technological equipment [6-7]. The advancement range of this technology has reached to it application in asphalt mixes as well. For instance, in one of the recent studies, the effect of nanoclay on rheological properties of binder has been investigated using penetration test, ductility test, softening point test, and dynamic shear rheometer. By conducting the above mentioned tests, researchers concluded that nanoclay has a significant effect on rheological properties of binders [8]. Additionally, the effect of using Zycosil nanomaterials on the reduction of moisture sensitivity of asphalt mixes in 2012 was investigated by Moghadas Nejad et al. [9]. results showed that adding zycosil to the made specimens causes a significant increase in the tensile strength ratio indicator 
of these specimens. In another research study, the moisture sensitivity of asphalt mixes made by basalt stone materials through adding SBR-Nanoclay composites was investigated. The obtained results showed that by adding this nanocomposite to the asphalt mix, the indirect tensile strength in dry and wet conditions increases [10]. The linear viscoelastic (LVE) properties of modified binders were investigated in another study using ethylene vinyl acetate nanocomposite and nanoclay. Results of this study showed that the proper compatibility between polymer and nanoclay leads to better distribution of polymer in binder and affects rheological properties of binder [11]

Raufi et al. [12] investigated the effect of using three types of nanomaterials on the properties of asphalt binder and asphalt mixture. The results of this study show that the use of nanomaterials can improve the performance of asphalt mixture at high temperatures and reduce the moisture sensitivity of these asphalt mixtures. Sohrabi et al. [13] evaluated the effect of aggregate coating with nano micronized calcium carbonate on the sensitivity of asphalt moisture. Theirs research shows that the use of calcium carbonate coatings reduces the moisture sensitivity of asphalt mixtures. On the other hand, the use of this coating of calcium carbonate improves the asphalt binder coverage on the aggregate surface. Moghdadas Nejad et al. [14] investigated the effect of nano-coating on aggregate surface in reducing moisture failure in asphalt mixtures. The results of this study show that the use of nano-coating on the aggregate surface reduces the amount of detachable energy and reduces the system's desire for the occurrence of nudity. The results of mechanical tests also showed that the resistance of the asphalt mixture to moisture decreased as a result of the coating on the surface of the aggregates. Razavi and Kavusi [15] investigated the effect of different nano additives on the moisture sensitivity of asphalt mixture. In this research, four types of materials, namely nano- $\mathrm{CaCO}_{3}$, nano-hydrated lime, nano-bentonite and nano-silica, and two types of anti-stripping fillers, namely hydrated lime and $\mathrm{CaCO}_{3}$ have been used. The results of this study show that the use of this nanomaterial has caused the system to reach a higher level in terms of resistance and its resistance to moisture sensitivity is reduced. Saltan et al. [16] evaluated the effect of nano $\mathrm{ZnO}$ on moisture sensitivity and permanent deformation of asphalt mixtures. The results show that the use of zinc nano-oxide reduces the tendency to stripping in asphalt mixtures. This material causes better adhesion and aggregation and also reduces the percentage of optimal asphalt binder. Recent studies indicate the growing trend of research in the field of nanomaterials effect on asphalt mixes properties [13, 17-19]. To this purpose, in the current research, the effect of using Nano $\mathrm{CuO}$, and Nano $\mathrm{SnO}_{2}$ on moisture damage of asphalt mixes was investigated using SFE components of binder, the aggregate-binder SFE, and the obtained results from cyclic loading tests under dry and wet conditions.

\subsection{Necessity of research and objectives}

Due to the proposed problems and the low rate of asphalt pavement useful life, especially in wet and rainy areas, in the current research attempts were made to prepare moisture resistant asphalt mixes using metal nanooxide materials added to binder.

The most important objectives of this research include:

- Investigating the effect of using metal nanooxeids on SFE components of binder;

- Investigating the effect of using metal nanooxeids on the aggregate-binder SFE parameters;

- Investigating the effect of using metal nanooxeids on the moisture sensitivity of asphalt mixes;

- Comparing the results obtained by loading tests under dry and wet conditions with those obtained by SFE method; and

- Investigating the mechanism of the effect of metal nanooxeids on the process of moisture damage occurrence under cyclic loading.

\section{Materials and laboratory program}

\subsection{Materials}

\subsubsection{Aggregates}

Two types of the base aggregates used in this research include limestone and granite. The main reason of using this type of aggregates was their different degree of water absorption, so that the effect of these aggregates with different minerals and different sensitivities on moisture damage can be assessed. The gradation of aggregate is mid limit of dense graded asphalt mixture. The physical properties of aggregates used in this research are presented in Table 1. It should be noted that the filler used in this research is the stone powder of those main aggregates.

\subsubsection{Nanomaterials}

In the current research 2 metal nanooxides called Nano

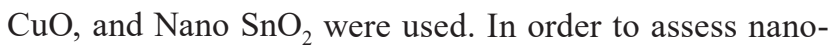
materials size and to investigate nanoparticles distribution in binder, electronic microscopy was used. These images were prepared in Tehran university laboratory. As shown 
Table 1 Physical and mineralogical characteristics of the aggregates used in this study

\begin{tabular}{|c|c|c|c|c|}
\hline Properties & Standard & Limestone & Granite & Specification limit \\
\hline \multicolumn{5}{|l|}{ Coarse aggregate } \\
\hline Bulk specific gravity $\left(\mathrm{g} / \mathrm{cm}^{3}\right)$ & & 2.63 & 2.61 & - \\
\hline SSD specific gravity $\left(\mathrm{g} / \mathrm{cm}^{3}\right)$ & ASTM C 127 [20] & 2.65 & 2.63 & - \\
\hline Apparent specific gravity $\left(\mathrm{g} / \mathrm{cm}^{3}\right)$ & & 2.68 & 2.67 & - \\
\hline \multicolumn{5}{|l|}{ Fine aggregate } \\
\hline Bulk specific gravity $\left(\mathrm{g} / \mathrm{cm}^{3}\right)$ & & 2.62 & 2.60 & - \\
\hline SSD specific gravity $\left(\mathrm{g} / \mathrm{cm}^{3}\right)$ & ASTM C 128 [21] & 2.65 & 2.62 & - \\
\hline Apparent specific gravity $\left(\mathrm{g} / \mathrm{cm}^{3}\right)$ & & 2.68 & 2.65 & - \\
\hline Specific gravity of filler $\left(\mathrm{g} / \mathrm{cm}^{3}\right)$ & ASTM D 854 [22] & 2.65 & 2.65 & - \\
\hline Los Angeles abrasion (\%) & ASTM C 131 [23] & 32 & 22 & $\operatorname{Max} 45$ \\
\hline Flat and elongated particles (\%) & ASTM D 4791 [24] & 9 & 6 & $\operatorname{Max} 10$ \\
\hline Sodium sulfate soundness (\%) & ASTM C 88 [25] & 7 & 9 & Max 10-20 \\
\hline Fine aggregate angularity & ASTM C 1252 [26] & 56.2 & 59.2 & Min 40 \\
\hline \multicolumn{5}{|l|}{ Mineralogical characteristics } \\
\hline $\mathrm{pH}$ & - & 7.8 & 6.7 & - \\
\hline $\mathrm{SiO} 2,(\%)$ & - & 18.6 & 62.9 & - \\
\hline $\mathrm{Al} 2 \mathrm{O} 3,(\%)$ & - & 3.2 & 13.4 & - \\
\hline $\mathrm{Fe} 2 \mathrm{O} 3,(\%)$ & - & 4.7 & 2.3 & - \\
\hline $\mathrm{MgO},(\%)$ & - & 1.4 & 0.8 & - \\
\hline $\mathrm{CaO},(\%)$ & - & 61.9 & 3.1 & - \\
\hline
\end{tabular}

in Figs. 1 and 2, images were prepared at $60000 \times$ magnification equal to a voltage of $15 \mathrm{KW}$. The apparent shape of this nanoparticle is almost circular. The following figures show the apparent shape of this nanoparticle. Copper oxide nanoparticles are more dispersed because of their heavy and coarse nature, while tin oxide nanoparticles due to their larger specific surface have a denser state. As in the previous research, nanomaterials percentage was selected to be between 0.5 and $1.00 \%$ of binder weight, the same percent was used in the current research.

\subsubsection{Binder}

The binder used in the current research is of pure binder type with 60-70 PEN asphalt binder supplied from Isfahan refinery. In order to mix nanoparticles with binder, at first, the binder is heated up to $150^{\circ}$, and within 30 minutes with specified intervals, nanoparticles are gradually added to mixing bowl with a speed of $10,000 \mathrm{rpm}$. Finally, mixing is continued at a temperature of $160 \mathrm{C}^{\circ}$ for 15 minutes.

\subsection{Laboratory program}

In the current research, attempts were made to use different combinations of asphalt mixes with different potentials against moisture damage. Therefore, 2 types of aggregates

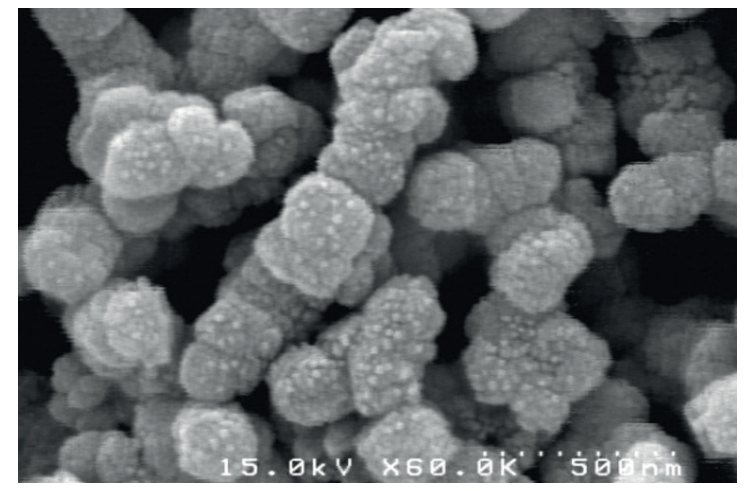

Fig. 1 Copper oxide nanoparticles used in this research

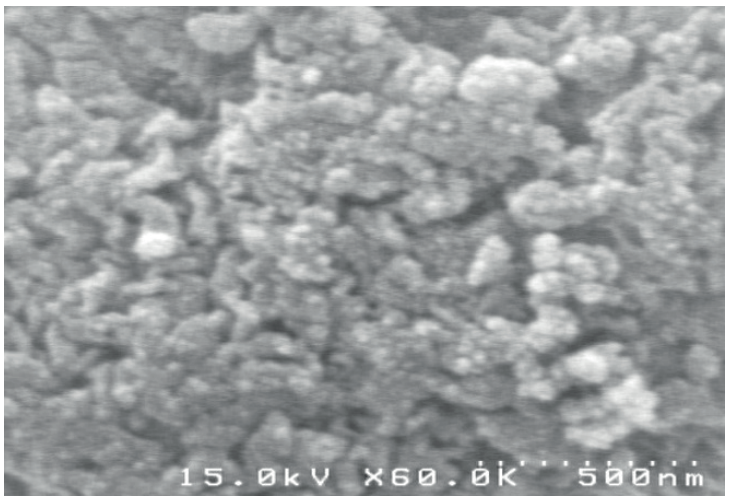

Fig. 2 Tin oxide nanoparticles used in this research 
(granite and limestone) with different mineralogical structures as well as 60-70 PEN base binder along with additives, including nano-copper oxide and nano-tin oxide were used in 2 different percentages of binder mass. By combining the mentioned materials, 10 different combinations of asphalt mixes are created, for each of them 6 asphalt mix specimens ( 3 specimens under dry conditions and 3 specimens under wet conditions) were made in laboratory in order to determine moisture sensitivity of different asphalt mixes. Additionally, some specimens were also made to determine the optimum binder content of the control mix. It should be noted that the test to determine the optimum binder content was done only for specimens made by control binder such that no different binder percentage exists amongst specimens with the same aggregate. The optimum binder content for lime and granite materials is shown in Tables 3 and 4 . The optimum binder was obtained by finding the mean of binder content corresponds to the maximum specific gravity, the maximum stability and $4 \%$ of the air voids. Moreover, values correspond to 5 parameters of stability, flow, AV, VMA, and VFA have been controlled by regulations values. As observed, the optimum binder content in the specimens made by granite aggregates is less than specimens made by limestone aggregates. Its main reason can be the smooth surfaces with less porosity in granite aggregates which reduce the absorption of unuseful binder.

As AASHTO T283 method is the most common laboratory simulation method under field conditions, in order to investigate the strength of asphalt mixes against moisture damage, AASHTO T283 standard was used to condition specimens in the current research. However, cyclic loading to determine the ratio of modulus in wet to dry conditions was used to determine the specimen's moisture sensitivity. Moreover, since the Durability and functionality of hot mix asphalts (HMA) depend on air voids and their characteristics [27], in this research the laboratory specimens were prepared in $7 \pm 1 \%$ of the air voids.

Table 2 Binder properties used in specimens

\begin{tabular}{|c|c|c|c|}
\hline \multicolumn{2}{|l|}{ Test method } & Specification & Test results \\
\hline \multicolumn{2}{|c|}{ Flash point AASHTO T48 } & $230^{\circ} \mathrm{C}$ & 295 \\
\hline \multicolumn{2}{|c|}{ Rotational viscosity@135 ${ }^{\circ} \mathrm{C}$} & 3.0 & 0.32 \\
\hline \multicolumn{2}{|l|}{ Test temperature ${ }^{\circ} \mathrm{C}$} & \multirow{2}{*}{ Min $1.00 \mathrm{kPa}$} & $\mathrm{G}^{*} / \sin \delta$ \\
\hline $64{ }^{\circ} \mathrm{C}$ & & & $3.1 \mathrm{kPa}$ \\
\hline \multicolumn{2}{|l|}{ Test temperature ${ }^{\circ} \mathrm{C}$} & \multirow{2}{*}{ Max $5000 \mathrm{kPa}$} & $\mathrm{G}^{*} \cdot \sin \delta$ \\
\hline $25^{\circ} \mathrm{C}$ & & & $2950 \mathrm{kPa}$ \\
\hline Test temperature ${ }^{\circ} \mathrm{C}$ & Stiffness MPa & $147 \mathrm{Mpa}$ & $\operatorname{Max} 300 \mathrm{MPa}$ \\
\hline$-22^{\circ} \mathrm{C}$ & m-value & 0.3299 & Min 0.30 \\
\hline
\end{tabular}

Table 3 Optimum binder content in specimens made with limestone aggregates

\begin{tabular}{|c|c|}
\hline Mixture & Specification \\
\hline Aggregate type & limestone \\
\hline $\begin{array}{l}\text { The binder content corresponds to the maximum } \\
\text { Marshall stability }\end{array}$ & 5.7 \\
\hline $\begin{array}{l}\text { The binder content corresponds to the maximum } \\
\text { bulk specific gravity }\end{array}$ & 5.8 \\
\hline The binder content corresponds to $4 \%$ of the air voids & 5.6 \\
\hline Optimum binder content & 5.7 \\
\hline
\end{tabular}

Table 4 Optimum binder content in specimens made with granite aggregates

\begin{tabular}{lc}
\hline Mixture & Specification \\
\hline Aggregate type & granite \\
$\begin{array}{l}\text { The binder content corresponds to the maximum } \\
\text { Marshall stability }\end{array}$ & 5.5 \\
$\begin{array}{l}\text { The binder content corresponds to the maximum } \\
\text { bulk specific gravity }\end{array}$ & 5.85 \\
$\begin{array}{l}\text { The binder content corresponds to 4\% of the air voids } \\
\text { Optimum binder content }\end{array}$ & 5.6 \\
\end{tabular}

Besides tests performed on asphalt mixes, some tests were also done to determine the aggregate and binder SFE components. In order to determine the aggregate SFE components and to determine the base and modified binder SFE components, the universal sorption device (USD) and sessile drop method were used, respectively. Fig. 3 shows the overall process of this research.

\subsection{Tests performed on asphalt mixes}

\subsubsection{The indirect tensile cyclic loading test}

In order to determine asphalt mixes modulus in loading cycles, repeated indirect tensile cyclic tests were done. In fact, this test is a fatigue test type in which the loading is applied to a cylinder specimen repeatedly. The specimen is loaded similar to resilient modulus test. But, the loading type is a half-sine load with a frequency time of $2 \mathrm{~Hz}$ (the loading time $0.1 \mathrm{~s}$ and resting time $0.4 \mathrm{~s}$ ) and the test was done at a Temperature of $25 \mathrm{C}^{\circ}$. Similar to indirect tensile strength, this test includes loading in line with the specimen diameter. In the current research, this test was done based on ASTM D7369 standard [12]. Fig. 4 shows how the specimen is placed in Universal Testing Machine (UTM). How loading and deformations occur is shown in Fig. 5.

In order to obtain stiffness modulus in each cycle, Eq. (1) is used. This value is calculated and represented in each cycle. 


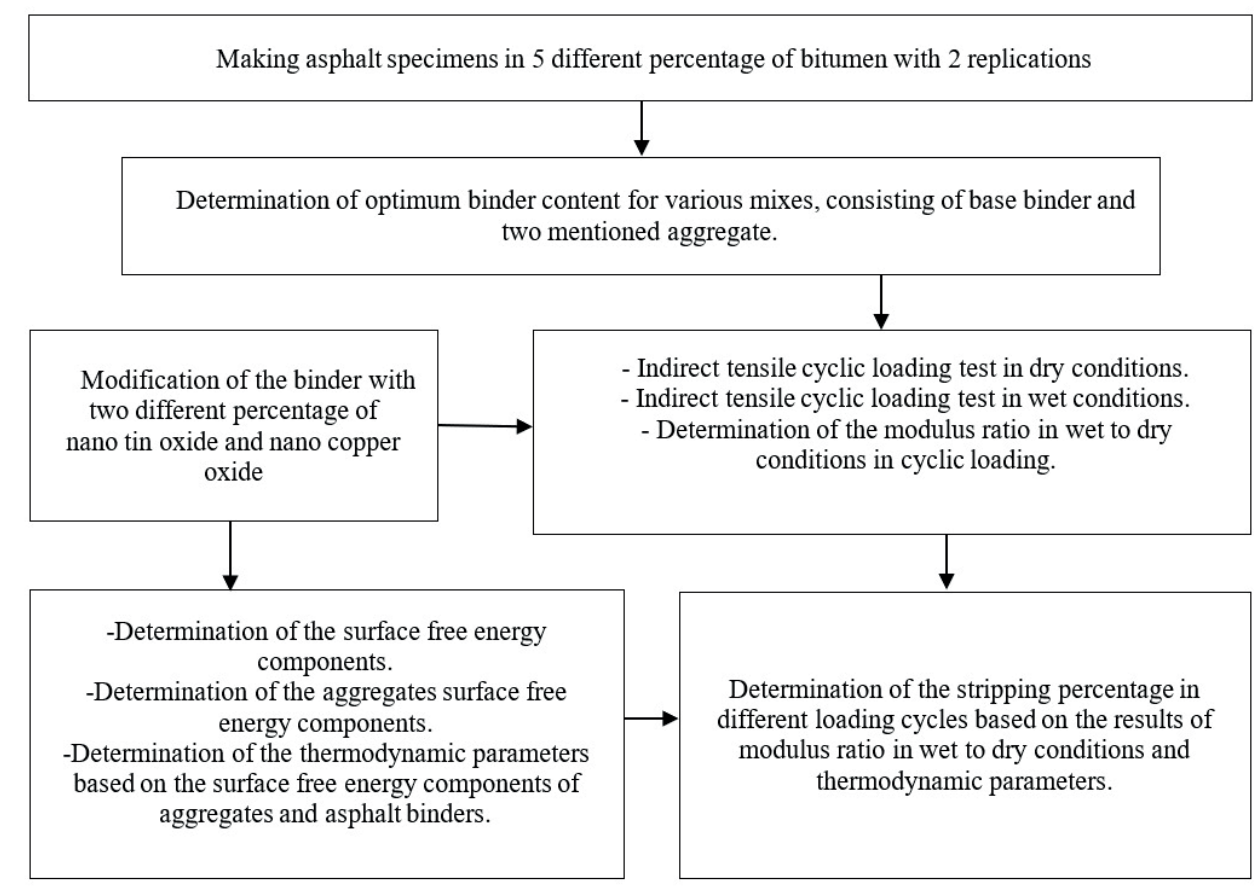

Fig. 3 Laboratory program in this research

$S M=\frac{P(v+0.27)}{H \times L}$,

where,

$S M=$ Stiffness modulus (MPa),

$P=$ The maximum Vertical repetitive force rate $(\mathrm{N})$,

$v=$ The Poisson's ratio (PR) of asphalt mix equals to 0.35 ,

$H=$ Reversible horizontal deformation ( $\mathrm{mm}$ ), and

$l=$ The height of specimen ( $\mathrm{mm}$ ).

The output used in this test is the stiffness modulus of asphalt mix in the dry and wet specimens. In order to determine the trend of changes relative to the asphalt mix stiffness and the stripping percentage of the surface of aggregate are used in loading cycles. To obtain moisture sensitivity using resilient modulus test, Eq. (2) is used.

$S M R=\left(S M_{w e t} / S M_{d r y}\right) \times 100$

where,

$S M R=$ Resilient modulus ratio $(\%)$,

$S M_{\text {wet }}=$ Stiffness modulus mean of wet specimens (kpa),

$S M_{d r y}=$ Stiffness modulus mean of dry specimens (kpa).

\subsubsection{Binder and aggregate SFE components measurement tests}

Measuring SFE components using sessile drop method is one of the common methods used today for solid materials. This method can be used both for aggregate and binder

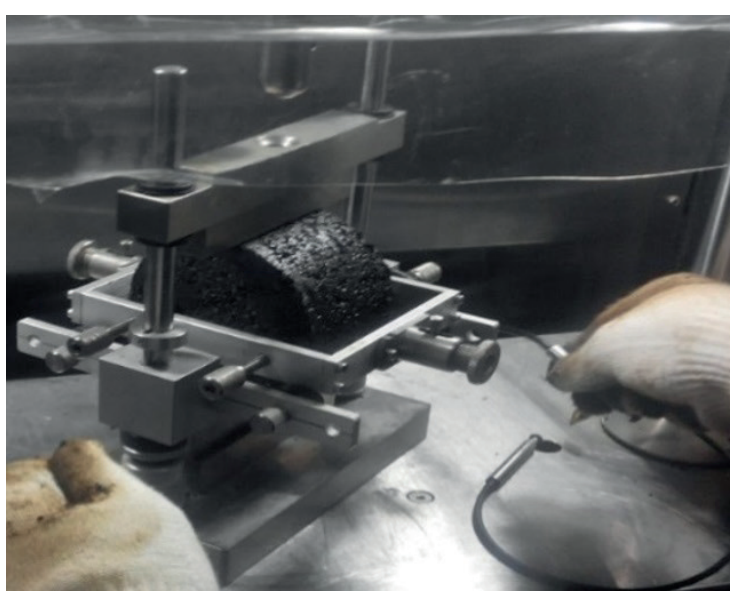

Fig. 4 Specimen placement in the test
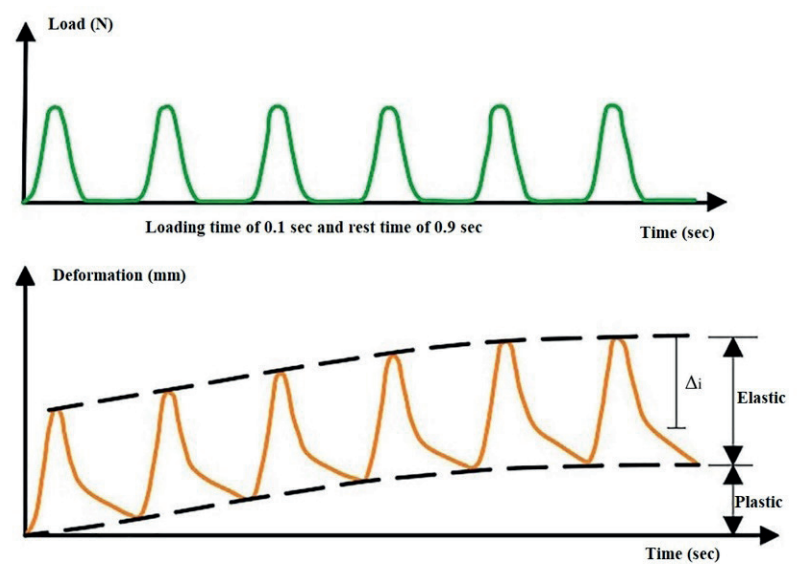

Fig. 5 Schematic of loading in the test [28] 


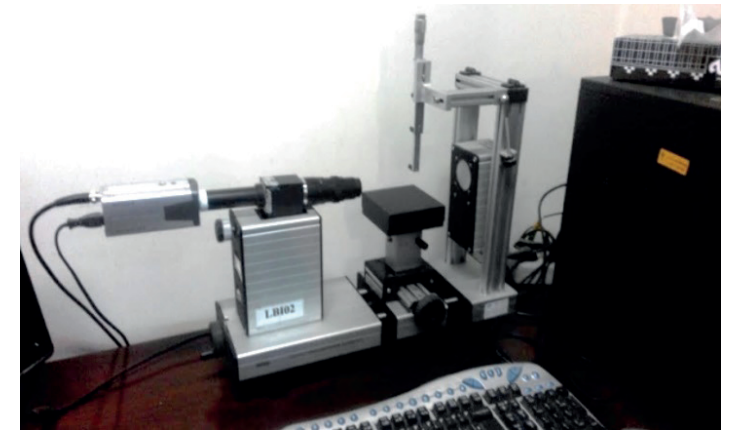

Fig. 6 Different parts of the sessile drop device

(in solid form), provided that the aggregate SFE components are small. The aggregate used in this research have large SFE components, and this method is not suitable to measure their SFE components. This experiment was conducted in the laboratory of Biocompatible Polymers Group of Iran Polymer and Petrochemical Research Center. The device used under G10 brand is made by the German CROSS factory. Fig. 6 shows a view of this device.

In order to measure the SFE components of aggregates, USD method can be used. As mentioned before, in this research, 2 types of aggregates were used. Given that the mine supplying aggregates used in this research is the same as the other research, results of that research were used in order to determine the SFE components of the used aggregates in this research [29].

\section{Results and discussion}

\subsection{Results of SFE method}

\subsubsection{Results of measuring the base and modified binders SFE components}

The aggregate-binder adhesion can be quantitatively determined if the SFE components of them are known. Moreover, the SFE is combined with other main properties using fracture mechanics fundamental principles in order to predict and model the growth of cracks in the asphalt mix. If damage is seen using these concepts, establishing a relationship between SFE and pavement damage will be easy, and the importance of SFE concept as a damage indicator in asphalt pavements will become more evident [30]. Results of measuring SFE components of the base and modified binder using different percentages of nanomaterials are shown in Table 5. These experiments were conducted in the Biocompatible Polymers laboratory of Iran Polymer and Petrochemical Research Center using sessile drop method. According to the previous studies it can be found that the binder has acidic properties and the acid component of the binder SFE is greater than its basic component.
Considering data shown in Table 4, it is obvious that the binder has acidic properties, such that the SFE of its acidic component is $3.18\left(\mathrm{ergs} / \mathrm{cm}^{2}\right)$, while its basic component is $1.16\left(\mathrm{ergs} / \mathrm{cm}^{2}\right.$ ) indicating that the adhesion between this material and acidic materials such as acidic aggregate is not desirable. This is one of the main reasons of the occurrence of damage induced by moisture in asphalt layers made by acidic aggregate. Data show that the use of nanoparticles has caused an increase in the total SFE of the base binder. This leads to better wettability of binder on the surface of the aggregates. Though wettability is different from adhesion, most of the previous papers have considered wettability as the first condition for good adhesion [31-33]. As it is obvious, using nanoparticles in this research caused the base binder acidic properties to be reduced and its basic properties to be increased. This leads to the improvement of modified binder adhesion compared to base binder in the acidic aggregates such as granite, which are sensitive to moisture damage. Additionally, this causes an increase in the initial energy required for the occurrence of stripping phenomenon and debonding of binder from acidic aggregates leading certainly to the speed reduction and the probable occurrence of moisture damage in asphalt mixes.

Results presented in Table 5 show that using nanoparticles used in this research has caused the acidic component of the base binder SFE to reduce from $3.18\left(\mathrm{ergs} / \mathrm{cm}^{2}\right)$ to $3.15\left(\mathrm{ergs} / \mathrm{cm}^{2}\right)$ in $0.5 \%$ of nano-tin oxide. Moreover, this amount has reduced to 3.14 (ergs/) in 1\% of nano-tin oxide. In the following it is observed that there is almost the same trend by adding nano-copper oxide, and using this material has caused a reduction in the amount of acidic component of the binder SFE. Increasing nano-copper oxide from $0.5 \%$ to $1 \%$ has caused the acidic component of the binder SFE to be reduced more.

Using nanoparticles has caused an increase in the basic component rate of the base binder SFE. As it is obvious from data shown in Table 5, using nanoparticles has caused basic properties of the base binder to be increased. It can be observed from the following table data that the basic component of the base binder SFE has increased from $1.16\left(\mathrm{ergs} / \mathrm{cm}^{2}\right)$ to $1.45\left(\mathrm{ergs} / \mathrm{cm}^{2}\right)$ and $1.49\left(\mathrm{ergs} / \mathrm{cm}^{2}\right)$ in the $0.5 \%$ and $1 \%$ of nano-copper oxide. This trend is also seen by adding nano-tin oxide causing an increase in the basic component of the Binder SFE. The higher percentage the nano-tin oxide, the greater increase in the basic component of the SFE is seen. As seen from the data obtained by measuring the binder SFE components, using nanoparticles has caused an increase in the basic-acidic (polar) 
properties of the binder. This can improve the adhesion of this material and the aggregates with high polar properties. The presented results show that the basic-acidic component of the SFE in the without additive state has been equal to $3.84\left(\mathrm{ergs} / \mathrm{cm}^{2}\right)$. Adding $0.5 \%$ and $1 \%$ of nano-tin oxide has caused this component to increase to $4.18\left(\mathrm{ergs} / \mathrm{cm}^{2}\right)$ and $4.30\left(\mathrm{ergs} / \mathrm{cm}^{2}\right)$, respectively. Also, a similar trend can be seen in the addition of nano-copper oxide that Adding $0.5 \%$ and $1 \%$ of nano-copper oxide has caused this component to increase to $4.23\left(\mathrm{ergs} / \mathrm{cm}^{2}\right)$ and $4.16\left(\mathrm{ergs} / \mathrm{cm}^{2}\right)$ respectively. Using nano-copper oxide and nano-tin oxide has caused a slight increase in non-polar SFE rate of the base binder based on Table 5. The only exception is about modified binders with $1 \%$ of nano-copper oxide. Using this material has caused a significant increase in the non-polar SFE rate of the binder. As it is obvious, the non-polar component of the binder SFE is by far greater than its polar component. In fact, the binder shows poor polar properties and most of its bonds are covalent (non-polar).

\subsubsection{Results of testing the aggregate SFE components}

Table 6 shows results of testing the aggregate SFE components. As observed from data presented in this table, the acidic component of the granite aggregate SFE is greater than that of lime aggregate SFE. The opposite trend exists for basic component of the SFE in which the basic component of the granite aggregate SFE is smaller than that of lime aggregate SFE. In addition, it is observed that the polar component of the aggregate SFE is higher indicating the higher polarity of granite aggregates used in this research. In fact, most of the bounds between aggregate-binder are formed by polar bonds. These bonds are easily broken down in the presence of the third polar material (water) and the binder stripping occurs on the aggregates surface. In the contrary, it is observed that the non-polar component of SFE of the limestone aggregates is higher than that of granite. This indicates the greater tendency to form non-polar bonds in the limestone aggregates.

\subsubsection{Adhesion free energy under dry and wet conditions}

As we know, the adhesion free energy is positive indicating that energy should be consumed to debond 2 materials, and the larger positive values show that better adhesion has been provided. Results of the adhesion free energy between aggregates and base and modified binders used in this research before and after modification using metal nano oxides are presented in Table 7. These results were obtained using SFE components of aggregates and base and modified binders presented in the 2 previous sections.

As shown in Table 7, the adhesion free energy between 2 materials is positive in all specimens, therefore, to debond them from each other, energy is needed. Results obtained by the aggregate-binder adhesion free energy column show that the adhesion between limestone aggregate and base binder is greater than that of the granite aggregate and base binder. This shows that debonding base binder from the limestone aggregate surface unit in dry condition (in the absence of water) is more difficult than granite aggregate surface and needs more energy. Additionally, results of this column show that using metal nanooxides has caused an increase in the adhesion SFE. Moreover, the energy required for failure at the aggregate-binder contact surface has increased in dry conditions as the percentage of nanomaterials used in this research increased.

Table 5 SFE components of base binder and modified asphalt binder

\begin{tabular}{|c|c|c|c|c|c|}
\hline SFE components & $\begin{array}{c}\text { Base asphalt } \\
\text { binder }\end{array}$ & $\begin{array}{c}0.5 \% \text { nano } \mathrm{SnO}_{2}^{-} \\
\text {modified asphalt } \\
\text { binder }\end{array}$ & $\begin{array}{c}1 \% \text { nano } \mathrm{SnO}_{2}- \\
\text { modified asphalt } \\
\text { binder }\end{array}$ & $\begin{array}{c}0.5 \% \text { nano } \mathrm{CuO}- \\
\text { modified asphalt } \\
\text { binder }\end{array}$ & $\begin{array}{c}1 \% \text { nano } \mathrm{CuO}- \\
\text { modified asphalt } \\
\text { binder }\end{array}$ \\
\hline Acid component (ergs/ $\mathrm{cm}^{2}$ ) & 3.18 & 3.15 & 3.14 & 3.09 & 2.90 \\
\hline Base component $\left(\mathrm{ergs} / \mathrm{cm}^{2}\right)$ & 1.16 & 1.39 & 1.47 & 1.45 & 1.49 \\
\hline Polar component $\left(\mathrm{ergs} / \mathrm{cm}^{2}\right)$ & 3.84 & 4.18 & 4.30 & 4.23 & 4.16 \\
\hline Nonpolar component (ergs $\left./ \mathrm{cm}^{2}\right)$ & 14.02 & 14.56 & 14.98 & 15.02 & 16.73 \\
\hline Total SFE $\left(\mathrm{ergs} / \mathrm{cm}^{2}\right)$ & 17.86 & 18.74 & 19.28 & 19.25 & 20.89 \\
\hline
\end{tabular}

Table 6 SFE components of two types of aggregates used in this research

\begin{tabular}{lcccc}
\hline Type of aggregate & Total SFE & Nonpolar component & Polar component & Basic component \\
\hline Granite & 293.79 & 57.53 & 236.26 & 534.25 \\
Limestone & 259.32 & 62.13 & 197.19 & 593.45 \\
\hline
\end{tabular}


Table 7 Adhesion SFE of various compounds in dry and wet conditions

\begin{tabular}{lcccccc}
\hline Mixture & Asphalt binder & Aggregate & $\begin{array}{c}\text { Asphalt binder- } \\
\text { aggregate }\end{array}$ & Asphalt-water & Water-aggregate & $\begin{array}{c}\text { Asphalt-binder in } \\
\text { presence of water }\end{array}$ \\
\hline 1 & $\mathrm{AC}$ & Granite & 150.25 & 63.85 & 355.88 & -119.88 \\
2 & $\mathrm{AC}+0.5 \% \mathrm{SnO}_{2}$ & Granite & 151.98 & 65.46 & 355.88 & -110.84 \\
3 & $\mathrm{AC}+1 \% \mathrm{SnO}_{2}$ & Granite & 153.44 & 66.69 & 355.88 & -111.44 \\
4 & $\mathrm{AC}+0.5 \% \mathrm{CuO}$ & Granite & 152.36 & 66.11 & 355.88 & -112.01 \\
5 & $\mathrm{AC}+1 \% \mathrm{CuO}$ & Granite & 153.25 & 67.72 & 355.88 & -115.99 \\
6 & $\mathrm{AC}$ & Limestone & 154.63 & 63.85 & 360.51 & -119.57 \\
7 & $\mathrm{AC}+0.5 \% \mathrm{SnO}_{2}$ & Limestone & 156.17 & 65.46 & 360.51 & -110.77 \\
8 & $\mathrm{AC}+1 \% \mathrm{SnO}_{2}$ & Limestone & 157.49 & 66.69 & 360.51 & -111.54 \\
9 & $\mathrm{AC}+0.5 \% \mathrm{CuO}^{2}$ & Limestone & 156.49 & 66.11 & 360.51 & -112.04 \\
\hline
\end{tabular}

\subsection{Results of repeated load in wet and dry conditions}

As aforementioned, considering data obtained from repeated load test and by knowing the rate of applied stress during each test, stiffness modulus is calculated using maximum strain and stress. The stiffness modulus values versus the number of loading cycles are determined for each specimen. In the current research, the stiffness modulus was calculated for all specimens in dry and wet conditions.

Results of the stiffness modulus in wet to dry conditions ratio for all specimens made by granite and limestone aggregates are shown in Figs. 7 and 8, respectively.

Considering data presented in these 2 figures, it is obvious that the stiffness modulus in the wet to dry conditions ratio is always less than 100 . This event is expected, because the destructive effect of water leads to the change of binder properties and losing adhesion on the binder -aggregate contact surface, both of them lead to the reduction of asphalt mix modulus in the wet conditions compared to the dry conditions. It was also evident from data presented in the adhesion free energy table in the dry and wet conditions that the binder-aggregate free energy values are negative in the wet conditions. This means that the system releases energy during the occurrence of stripping. According to the thermodynamic concepts, each process that releases energy is spontaneous and occurs under any circumstances. The presented results show that using 2 types of nano copper and nano-tin oxides additives in the binder causes an increase in the stiffness modulus in the wet to dry conditions ratio. This means that the loss of stiffness modulus has reduced in wet conditions compared to dry conditions. In fact, modifying binder by nanoadditives has led to the occurrence of the lower rate of strength loss in asphalt mixes in the presence of water. The positive effect of using binder modification via nanoparticles in the asphalt mixes has been more

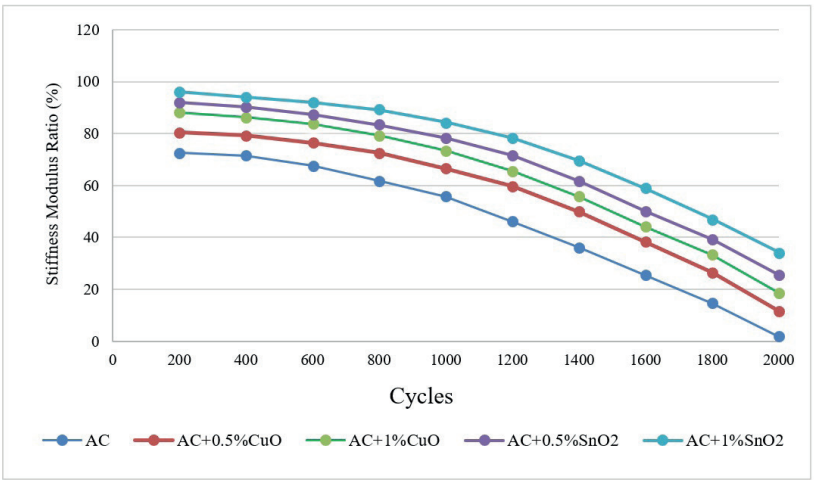

Fig. 7 Dynamic modulus ratio in specimens made with granite aggregates

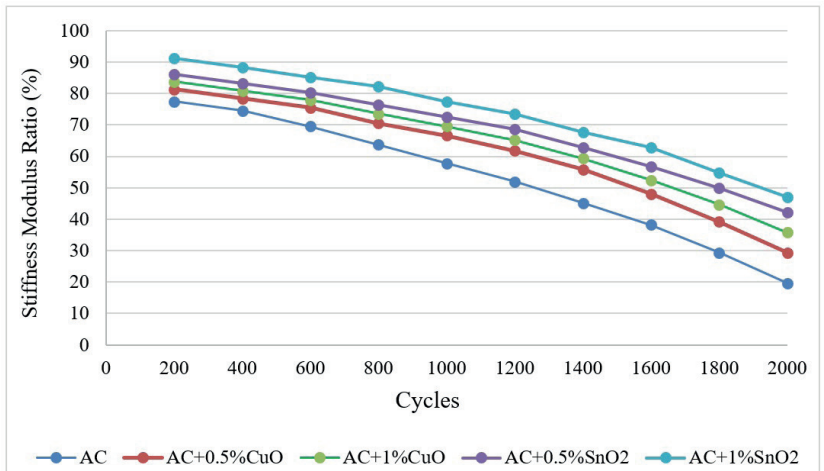

Fig. 8 Dynamic modulus ratio in specimens made with limestone aggregates

evident in the number of higher cycles. As observed, the specimens made by modified binders using nano-tin oxide outperformed control specimens and specimens made by binders modified by nano-copper oxide.

Results of dynamic modulus of wet to dry conditions ratio in specimens made by granite aggregates are shown in Fig. 7. A similar trend can be observed in this group specimens in comparison to those made by limestone 
aggregate (Fig. 8). It should be noted that, in the general state, the wet to dry stiffness modulus in specimens made by granite aggregates has been less than acidic aggregates. Additionally, it is observed that reduction slope of stiffness modulus ratio shows a sharper trend due to using granite aggregates compared to limestone aggregates indicating the higher speed of reduction in stiffness modulus under wet conditions in acidic aggregate. Using binder modification has led to the more improvement of asphalt mixes made by granite aggregates against moisture.

\subsection{Stripping process in repeated loading cycles}

Using the results of dynamic modulus in wet to dry conditions ratio presented in Figs. 7 and 8 as well as results of measuring adhesion free energy in the presented dry and wet conditions, the stripping percentage of binder from the aggregates surface was calculated and shown in Figs. 9 and 10. As shown in figures, using both types of metal nanooxides has led to the reduction of the stripping percentage of the aggregates surface in different cycles of loading. This means that the coverage on the aggregates surface does not allow moisture to penetrate into the aggregate- binder contact surface leading to the increase of asphalt mix strength to moisture. The increase in the percentage of the additives used in this research has led the stripping rate to be more reduced. Additionally, in both series of specimens made by granite and limestone aggregates, it is observed that binder modification with nanotin oxide has more affected the reduction of stripping percentage in loading cycles.

Moreover, studies show that specimens made by granite aggregate had poorer performance in comparison to the specimens made by limestone aggregate. The main reason of this event can be attributed to the stronger adhesion of basic aggregate with binder, which is an acidic material. Furthermore, in the previous sections, it was observed that the failure at the contact surface of binder-granite aggregate has caused greater energy to be released in comparison to binder-limestone aggregates. In fact, the tendency to stripping in the specimens made by granite aggregates is greater. Considering the data

Presented in these figures it can be observed that the slop of the stripping percentage against loading cycles diagram is ascending. In fact, in the initial loading cycles, approximately all aggregates and binder have bonded to each other. The more the specimens are exposed to wet conditions and the more the number of repetitions, the

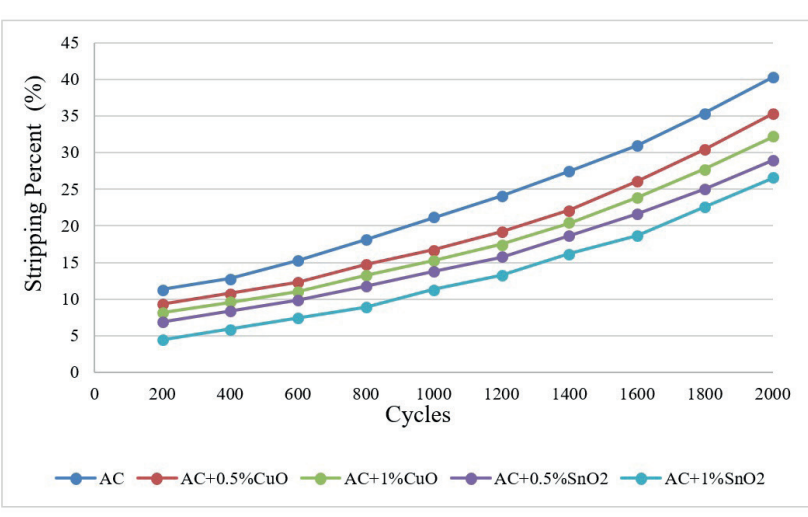

Fig. 9 Stripping of the binder film from the aggregates surface in specimens made with granite aggregates

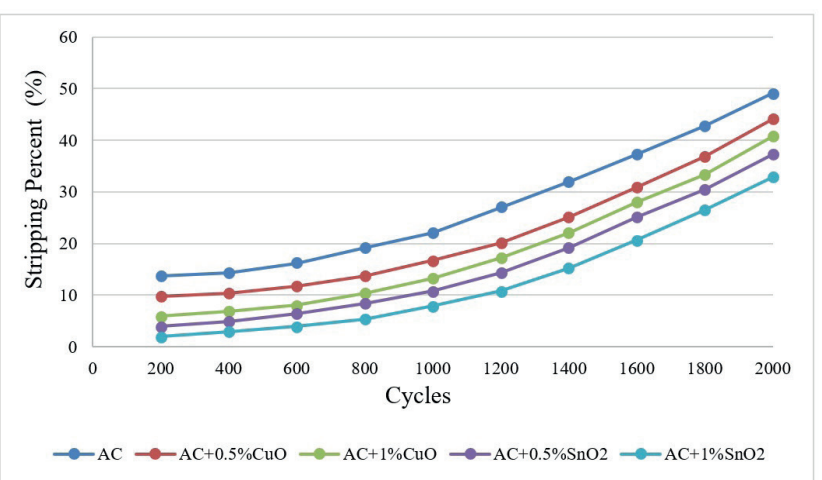

Fig. 10 Stripping of the binder film from the aggregates surface in specimens made with limestone aggregates

higher percentage of the binder is stripped from the aggregates surface. As a result, the reduction of adhesion and the reduction of the percentage of the aggregate bonded together have negatively affected each other and the moisture damage occurrence continues with sharper slope. In addition, it is observed that the stripping process slope is greater in the specimens made by base binders.

\section{Conclusions}

Considering the importance of moisture damage and the effect of the used materials properties on this damage, research on the effect of nanomaterials on asphalt mixes properties have experienced a growing trend in recent years. Accordingly, in the current research attempts have been made to investigate the role of 2 nanomaterials (Nano $\mathrm{CuO}$, and $\mathrm{Nano} \mathrm{SnO}_{2}$ ) in the moisture sensitivity of various asphalt mixes. The most important results obtained in this research include:

- The acidic component of granite aggregates SFE is greater than that of limestone aggregates SFE. The opposite process exists for SFE of basic component. 
- Using nanoparticles in this research has caused acidic properties of base binder to be reduced and its basic properties to be increased. This leads to the improvement of modified binder adhesion compared to base binder with regard to acidic aggregates such as granite, which are sensitive to moisture damage.

- Results of the binder-aggregate adhesion free energy show that the adhesion between limestone aggregates and base binder is greater that the adhesion between granite aggregates and base binder. This indicates that in dry conditions (in the absence of water) debonding base binder from the limestone aggregates surface unit is more difficult than granite aggregates surface and needs more energy. Moreover, using metal nanooxides has caused an increase in the aggregate-binder adhesion free energy.

- The specimens made by granite aggregates and base binder had more negative adhesion free energy compared to limestone aggregates. This shows that due to debonding binder from the surface of the aggregates unit with the water penetration, higher energy is released, and therefore, the tendency to stripping is higher in these aggregates.

\section{References}

[1] Moghadas Nejad, F., Azarhoosh, A. R., Hamedi, Gh. H., Azarhoosh, M. J. "Characterization of permanent deformation resistance of precipitated calcium carbonate modified asphalt mixture", International Journal of Civil Engineering and Management, 21(5), pp. 615-622, 2015.

https://doi.org/10.3846/13923730.2014.890654

[2] Moghadas Nejad, F., Azarhoosh, A.R., Hamedi, Gh. H. "Laboratory Evaluation of Using Recycled Marble Aggregates on the Mechanical Properties of Hot Mix Asphalt", Journal of Materials in Civil Engineering, 25(6), pp. 741-746, 2013.

https://doi.org/10.1061/(ASCE)MT.1943-5533.0000539

[3] Caro, S., Masad, E., Bhasin., A., Little, D. N. "Moisture susceptibility of asphalt mixtures, Part 2: characterisation and modelling", International Journal of Pavement Engineering, 9(2), pp. 99-114, 2008.

https://doi.org/10.1080/10298430701792144

[4] Azarhoosh, A. R., Hamedi G. H., Abandansari, F. H. "Providing Laboratory Rutting Models for Modified Asphalt Mixes with Different Waste Materials", Periodica Polytechnica Civil Engineering, 62(2), pp. 308-317, 2018.

https://doi.org/10.3311/PPci.10684

[5] Caro Spinel, S. "A Coupled Micromechanical Model of MoistureInduced Damage in Asphalt Mixtures: Formulation and Applications", PhD Dissertation Texas A\&M University, 2009. [online] Available at: http://hdl.handle.net/1969.1/ETD-TAMU-2009-12-7336
- Using 2 types of nano-copper and nano-tin oxides additives in the binder causes an increase in the stiffness modulus in the wet to dry conditions ratio. This means that the loss of stiffness modulus has reduced in the wet conditions compared to dry conditions. In fact, modifying binder by nanoadditives has led to the occurrence of the lower rate of strength loss in asphalt mixes in the presence of water.

- The reduction slope of stiffness modulus ratio shows a sharper trend due to using granite aggregates compared to limestone aggregates indicating the higher speed of reduction in stiffness modulus under wet conditions in acidic aggregate. Using binder modification has led to the more improvement of asphalt mixes made by granite aggregates against moisture.

- Using both types of metal nanooxides in this research has led to the reduction of the stripping percentage of the aggregates surface in different cycles of loading. This means that the coverage on the aggregates surface does not allow moisture to penetrate into the aggregate- binder contact surface leading to the increase of asphalt mix strength to moisture.

[6] Azarhoosh, A., Abandansari, H. F., Hamedi, G. H. "Surface-Free Energy and Fatigue Performance of Hot-Mix Asphalt Modified with Nano Lime", Journal of Materials in Civil Engineering, 31(9), 2019. https://doi.org/10.1061/(ASCE)MT.1943-5533.0002836

[7] Wang, J. "Nanomaterial-based electrochemical biosensors", Analyst, 130(4), pp. 421-426, 2005.

https://doi.org/10.1039/B414248A

[8] Jahromi, S. G., Khodaii, A. "Effects of nanoclay on rheological properties of bitumen binder", Construction and Building Materials, 23(8), pp. 2894-2904, 2009.

https://doi.org/10.1016/j.conbuildmat.2009.02.027

[9] Moghadas Nejad, F., Azarhoosh, A. R., Hamedi, Gh. H., Azarhoosh, M. J. "Influence of using nonmaterial to reduce the moisture susceptibility of hot mix asphalt", Construction and Building Materials, 31, pp. 384-388, 2012.

https://doi.org/10.1016/j.conbuildmat.2012.01.004

[10] Rajasekar, R., Heinrich, G., Das, A. Das, C. K. "Development of SBR-Nanoclay Composites with Epoxidized Natural Rubber as Compatibilizer", Journal of Nanotechnology, 2009, Article ID: 405153, 2009.

https://doi.org/10.1155/2009/405153

[11] Sadeghpour Galooyak, S., Dabir, B., Nazarbeygi, A. E., Moeini, A. "Rheological properties and storage stability of bitumen/SBS/ montmorillonite composites", Construction and Building Materials, 24(3), pp. 300-307, 2010.

https://doi.org/10.1016/j.conbuildmat.2009.08.032 
[12] Raufi, H., Topal, A., Sengoz, B., Kaya, D. "Assessment of Asphalt Binders and Hot Mix Asphalt Modified with Nanomaterials", Periodica Polytechnica Civil Engineering, 64(1), pp. 1-13, 2020. https://doi.org/10.3311/PPci.14487

[13] Sohrabi, M., Shirmohammadi, H., Hamedi, G. H. "Investigating the Effect of Modifying Aggregate Surface by Micronized Calcium Carbonate on Increasing the Moisture Resistance of Asphalt Mixtures". Periodica Polytechnica Civil Engineering, 63(1), pp. 63-76, 2019.

https://doi.org/10.3311/PPci.11632

[14] Moghadas Nejad, F., Asadi, M., Hamedi, Gh. H., Esmaeeli, M. R. "Using Hydrophobic Coating on Aggregate Surfaces to Reduce Moisture Damage in Asphalt Mixture", Materials in Civil Engineering, 30(10), pp. 1432-1437, 2018. https://doi.org/10.1061/(ASCE)MT.1943-5533.0002413

[15] Razavi, S.-H., Kavussi, A. "The role of nanomaterials in reducing moisture damage of asphalt mixes", Construction and Building Materials, Article number: 117827, 2020. https://doi.org/10.1016/j.conbuildmat.2019.117827

[16] Saltan, M., Terzi, S., Karahancer, S. "Mechanical Behavior of Bitumen and Hot-Mix Asphalt Modified with Zinc Oxide Nanoparticle", Journal of Materials in Civil Engineering, 31(3), Article number: 04018399, 2019. https://doi.org/10.1061/(ASCE)MT.1943-5533.0002621

[17] Behbahani, H., Hamedi, G. H., Moghaddam Gilani, V. N. "Effects of asphalt binder modifying with nano hydrated lime on moisture susceptibility of asphalt mixtures with thermodynamically concepts", Petroleum Science and Technology, 38(4), pp. 297-302, 2020. https://doi.org/10.1080/10916466.2019.1702685

[18] Hamedi, G. H. "Investigating the Use of Nano Coating Over the Aggregate Surface on Moisture Damage of Asphalt Mixtures", International Journal of Civil Engineering, 16, pp. 659-669, 2018. https://doi.org/10.1007/s40999-016-0143-x

[19] Hamedi, G. H., Azarhoosh, A. R., Khodadadi, M. "Effects of Asphalt Binder Modifying with Polypropylene on Moisture Susceptibility of Asphalt Mixtures with Thermodynamically Concepts", Periodica Polytechnica Civil Engineering, 62(4), pp. 901-910, 2018. https://doi.org/10.3311/PPci.11570

[20] ASTM "C127 - 15 Standard Test Method for Relative Density (Specific Gravity) and Absorption of Coarse Aggregate", ASTM International, West Conshohocken, PA, USA, 2015. https://doi.org/10.1520/C0127-15

[21] ASTM "C128 - 15 Standard Test Method for Relative Density (Specific Gravity) and Absorption of Fine Aggregate", ASTM International, West Conshohocken, PA, USA, 2015. https://doi.org/10.1520/C0128-15

[22] ASTM "D854 - 14 Standard Test Methods for Specific Gravity of Soil Solids by Water Pycnometer", ASTM International, West Conshohocken, PA, USA, 2014. https://doi.org/10.1520/D0854-14
[23] ASTM "C131 / C131M - 20 Standard Test Method for Resistance to Degradation of Small-Size Coarse Aggregate by Abrasion and Impact in the Los Angeles Machine", ASTM International, West Conshohocken, PA, USA, 2020 https://doi.org/10.1520/C0131_C0131M-20

[24] ASTM "ASTM D4791 - 19 Standard Test Method for Flat Particles, Elongated Particles, or Flat and Elongated Particles in Coarse Aggregate", ASTM International, West Conshohocken, PA, USA, 2019.

https://doi.org/10.1520/D4791-19

[25] ASTM "ASTM C88 - 13 Standard Test Method for Soundness of Aggregates by Use of Sodium Sulfate or Magnesium Sulfate", ASTM International, West Conshohocken, PA, USA, 2013. https://doi.org/10.1520/C0088-13

[26] ASTM "ASTM C1252 - 17 Standard Test Methods for Uncompacted Void Content of Fine Aggregate (as Influenced by Particle Shape, Surface Texture, and Grading)", ASTM International, West Conshohocken, PA, USA, 2017. https://doi.org/10.1520/C1252-17

[27] Lublóy, É., Ambrus, D., Kapitány, K., Barsi, Á. "Air Void Distribution of Asphalts Determined by Computed Tomography", Periodica Polytechnica Civil Engineering, 59(4), pp. 503-510, 2015. https://doi.org/10.3311/PPci.7608

[28] Sebaaly, P. E. "ComparisonofLime andLiquid Additives onthe MoistureDamage of Hot Mix Asphalt Mixtures, National Lime Association, Arlington, VI, USA, 2007. [online] Available at: https://www.lime.org/documents/publications/free_downloads/ moisture-damage-asphalt.pdf

[29] Hamedi, Gh. H. "Evaluating the effect of asphalt binder modification using nanomaterials on the moisture damage of hot mix asphalt", Road Materials and Pavement Design, 18(6), pp. 1375-1394, 2016. https://doi.org/10.1080/14680629.2016.1220865

[30] Bose, A. "Measurement of Work of Adhesion Between Asphalt and Rock", University of Rhode Island, Kingston, RI, USA, 2002.

[31] Hamedi, Gh. H., Moghadas Nejad, F. "Evaluating the Effect of Mix Design and Thermodynamic Parameters on Moisture Sensitivity of Hot Mix Asphalt", Journal of Materials in Civil Engineering, 29(2), 2017. https://doi.org/10.1061/(ASCE)MT.1943-5533.0001734

[32] Tarrer, A. R., Wagh, V. "The effect of the physical and chemical characteristics of the aggregate on bonding, Strategic Highway Research Program", National Research Council, Washington, DC, USA, 1991.

[33] Zollinger, C. J. "Application of surface energy measurements to evaluate moisture susceptibility of asphalt and aggregates", $\mathrm{PhD}$ Dissertation, Texas A\&M University, 2005. [online] Available at: http://hdl.handle.net/1969.1/2320 